\title{
El patrimonio cultural en la formación de los profesionales del turismo en el Perú, 2018
}

\section{Cultural heritage in the training of tourism professionals in Peru, 2018}

\author{
Fabrizio Augusto Alberca Sialer* \\ Escuela Profesional de Turismo y Hotelería, \\ Universidad de San Martín de Porres, Perú
}

\section{Resumen}

El profesional del turismo se enfrenta a diversos retos en su formación y vida profesional. La presentación del patrimonio cultural es uno de ellos, pues debe conectar sus particularidades y valores con las expectativas y características de los turistas. Se ha evaluado la presencia de temas vinculados al patrimonio durante el proceso formativo, en planes y mallas curriculares. Para ello, se clasifican los cursos relacionados con el patrimonio en cuatro grupos: Patrimonio, Naturaleza, Turismo cultural y Sostenibilidad, los que representan el $5.5 \%$ de cursos y $6.1 \%$ de creditaje de la carrera. Se resalta que $41.7 \%$ de la oferta académica de pregrado se concentra en Lima. Además, se considera que el número promedio de cursos relacionados al uso turístico sostenible y responsable del patrimonio es reducido e insuficiente: 3.7 durante los diez semestres, asumiendo que debería incluirse cinco cursos como mínimo, un curso cada dos semestres.

Palabras clave: turismo, profesional, patrimonio, universidad. 


\begin{abstract}
Tourism professionals face several challenges in their training and professional life. Cultural heritage is one of them, since it must connect its special features and values with the expectations and characteristics of tourists. Therefore, the inclusion of topics related to heritage has been evaluated in the tourism program's curricula and curriculum grids during the training process. To that end, subjects related to heritage have been classified into four groups: Heritage, Nature, Cultural Tourism, and Sustainability, which represent 5.5\% and $6.1 \%$ of the program's subjects and credits, respectively. It is worth mentioning that $41.7 \%$ of the undergraduate academic offering is concentrated in Lima. Moreover, it is considered that the average number of subjects related to the sustainable and responsible tourist use of heritage is small and insufficient: 3.7 in 10 semesters. It is believed that at least 5 subjects should be included: 1 subject every 2 semesters.
\end{abstract}

Keywords: tourism, professional, heritage, university.

\title{
Introducción
}

Se plantea como objetivo de la presente investigación, analizar la formación del profesional del turismo en lo referente al patrimonio cultural, así como resaltar la labor y preparación multitemática, amplia y compleja de este profesional. Además, establecer la presencia del tema patrimonio durante el proceso formativo, mediante el análisis de los planes y mallas curriculares que las universidades ofrecen en la carrera de turismo. Para tales efectos, se revisa algunos aspectos teóricos-conceptuales que permitan contextualizar las necesidades académico-formativas de quienes se dedican a generar experiencias.

Dichas experiencias solo pueden ser reales, o dicho de otro modo, el desplazamiento por turismo se concretará siempre que exista alguna motivación que lleve a las personas a viajar; si existe algo que atraiga al visitante hacia otro lugar, uno distinto al de su residencia habitual; algo que logre hacerlo desplazarse. Entonces, la visita para conocer lugares y sitios, para ver objetos o vivenciar manifestaciones y experimentar, será siempre 
irremplazable. Mejor dicho, ningún turista viaja solo para moverse sin más. Lo hace porque existe una motivación que lo impulsa a salir, y este 'motor propulsor' lo constituyen los atractivos turísticos, además que se explica por sí mismo. Para el caso de este trabajo, ese atractivo turístico será el patrimonio cultural, con toda la complejidad que este implica.

Lo expuesto, permite hacer una aclaración con respecto a la relación patrimonio cultural o natural-atractivo turístico. Habrá que tener en cuenta, que el patrimonio cultural será siempre primero de, y para, la sociedad vinculada a él, y solo después para los visitantes, es decir, solo después podrá ser considerado como un recurso o atractivo turístico.

Por otro lado, cabe indicar que en el turismo actual los trabajadores juegan un rol importante en la construcción de la experiencia o vivencia del turismo. Urry (2004), va más allá e incluso sostiene que la interacción entre los trabajadores del turismo (o proveedores de servicios) y los consumidores forma parte del producto comprado. Agrega asimismo que «los servicios brindados a los turistas tienen que entregarse en el mismo momento y lugar en que se produce» (p. 45). Esto último pone -también- el foco sobre los profesionales del turismo ${ }^{1}$, quienes deben estar preparados para equilibrar la producción del servicio (servucción) con la prestación del mismo y la planificación para su desarrollo a todo nivel, así como su gestión. Y es que los turistas esperan un servicio de altísima calidad, pues para ellos el viajar se convierte en un «evento dotado de un significado especial» (Urry, 2004, p. 45). Por ende, serán muy críticos de los servicios que no los convenza, y de los espacios mal planificados y/o gestionados. O sea, se está frente a un turista más exigente.

Fayós planteó hace algunos años la llegada de la «Nueva Era del Turismo» (Serra, 1999, p. 4) como un espacio temporal en el que los consumidores son más expertos, más independientes, más activos, más cultos, y donde los valores como el respeto al medio natural y cultural están más

1 Si bien es posible usar el término «turismólogo» para designar a quien ha estudiado o estudia al turismo y lo concibe como una actividad amplia, dinámica, compleja (gestión, patrimonio, política) y cercana, incluso a las ciencias sociales, este término no es de uso y aceptación general, por tal motivo se denominará, en este escrito, como profesional del turismo a quien estudie o haya estudiado la carrera de turismo. 
presentes. Otros autores (Shaw et al., 2004, p. 117) reafirman esta teoría asegurando que el crecimiento del turismo posfordista nos conduce hacia productos especializados y nichos de mercado específicos, que provocan gran volatilidad en las preferencias de consumo debido al incremento de modelos no masificados y más funcionales. (como se citó en Sariego, 2014, p. 48)

La responsabilidad de los profesionales del turismo gana relevancia en el contexto antes descrito, en el que las principales características son el rechazo del turista al turismo de masas, es decir, al trato semejante, al que se le considere parte de una masa indiferenciada (Urry, 2004); y su interés y respeto por la cultura y naturaleza. «El turismo es prefigurativamente postmoderno, dada su particular combinación de lo visual, lo estético, lo comercial y lo popular» (Urry, 2004, p. 90). Todo lo anterior implica un trato y la creación de experiencias casi personalizadas para los turistas. En consecuencia, la preparación del profesional de los viajes es fundamental, y esta debe ser responsable y estar enfocada hacia la sostenibilidad (a sus pilares económico, ambiental y sociocultural), que lo lleve a convertirse en un profesional de las experiencias (satisfactorias y duraderas) y del desarrollo.

Así también, el turismo es un fenómeno transversal a las sociedades actuales, de esto hablan los 1323 millones de desplazamientos por el mundo en 2017 (Organización Mundial del Turismo - OMT, 2018), por lo que no puede ni debe ser soslayado. Pastor (2003) es lo suficientemente elocuente cuando dice que vivimos una «cultura de encuentro» en la que el turismo es el principal exponente, al menos, si se habla de encuentros físicos.

Entonces, las sociedades en su conjunto y los profesionales en particular deben prepararse para los retos que estos desplazamientos masivos imponen. Deberán para ello, permitir el encuentro sostenible entre turismo y el patrimonio (Martorell, 2017) ${ }^{2}$.

2 El último libro del Dr. Alberto Martorell ha sido publicado por la Universidad de San Martín de Porres (Lima, Perú) en 2017, y lleva como título Turismo cultural: reflexiones para un encuentro sostenible entre turismo y cultura. 


\section{El patrimonio cultural}

El patrimonio cultural debe entenderse como el conjunto de bienes y manifestaciones propios de una comunidad; como aquellos elementos tangibles e intangibles que los integra y los reconoce, y que además debería permitirles mejorar su calidad de vida: es un fin, pero puede, de algún modo, ser un medio siempre que se use respetuosa y sosteniblemente. El patrimonio (tangible e intangible) de una sociedad es una construcción que adquiere «una fuerza simbólica extrema (...) se tornan representaciones de tiempos, espacios y acontecimientos específicos» (Carvalho \& Funari, 2012, p. 106). El patrimonio le da sentido a la vida en sociedad; les brinda la oportunidad en otras palabras, de construir un nosotros. Para ello, antes se debe tener claro que «es mediante la apropiación e identificación con él que un bien cultural deja de ser una cosa y se convierte en un referente cultural para la comunidad local»; se convierte por fin en su patrimonio cultural (Alberca, 2014, p. 89).

Ergo, cuando se use este patrimonio (nótese que no se pone en discusión la posibilidad de uso) se deberá considerar que en el fondo es una construcción de la sociedad; son ellos quienes le atribuyen un valor que, de hecho, no tiene que ser compartido necesariamente por otro grupo; «es algo artificial, que pese a lo físico y material, descansa en su valor simbólico o hace referencia a ideas y valores; y sobre estas suele sustentarse la identidad» (Prats, 1997, como se citó en Elías, 2009, p. 25).

Martorell (2017), sostiene que el patrimonio es materia y símbolo. Ambos componentes son importantes y dependientes entre sí, por lo que, ya visto desde, o para el turismo, los intermediarios a todo nivel (o sea, los profesionales del turismo), preferentemente no pueden ni deben desvirtuar alguno de estos elementos constitutivos. Por el contrario, deberán ser los primeros promotores y defensores del cuidado del valor simbólico y del material mientras ejercen su labor profesional. Esta obligación se complejiza si se piensa en el poder de los símbolos globales que, por diferentes medios, incluidas las visitas turísticas, arriban a los destinos afectándolos no siempre positivamente. El profesional del turismo debe saber dar respuesta. 


\section{Usos sociales del patrimonio: el turismo}

El patrimonio cultural no son bienes y manifestaciones que descansan en el tiempo y que, por ende, se encuentran desconectadas de la realidad, lejos del presente y más aún del futuro; y de lo cotidiano además. No, el patrimonio se ha de entender como el conjunto de expresiones que, si bien vienen del pasado (no siempre lejano), se encuentran en el ahora y se deberían proyectar al futuro, a un después.

En efecto, patrimonio se conjuga en presente. En presente continuo, pleno de vida en el tiempo actual, de clarísima raíz local pero con simbología universalizable, con pretensión no de permanencia sino -y sobre todo- de vigencia. Como consecuencia lógica, también de trascendencia. Y si no se conjuga así, carece de sentido dedicarle la atención como parte de la vida social (Martorell, 2017, p. 51).

El patrimonio, por su propia constitución le pertenece a todos y, por lo tanto, todos deben poder disfrutarlo, sin importar el tiempo en que se conjugue, pues está aquí, ahora, entre nosotros. Debe, como bien ha dicho el Dr. Martorell, estar vigente y trascender; piénsese ahora en estos dos términos vinculados a la razón de ser del patrimonio y su proyección.

Una vez contextualizado el uso del patrimonio cultural en general, se avanzará hacia el turismo como un modo de uso. Para ello el artículo Los usos sociales del Patrimonio Cultural, de Néstor García Canclini (1999) será de ayuda.

Lo primero que se debe considerar, para ser coherentes con la idea de patrimonio, es que su uso debe priorizar siempre al local, no al foráneo ${ }^{3}$, quien es un actor temporal, y los efectos negativos por un eventual mal uso no lo alcanzará en su vida cotidiana. Además, pues, por un tema de 'propiedad emocional', si se permite el término, es, o debería ser el dueño, el local, el receptor (este último si se mira desde el turismo), el primer beneficiario de su uso.

Martorell (2017), por su lado, enfatiza lo insustancial de estos términos: local y foráneo o turista, pues el uso de estos términos no permite identificar con precisión sus actitudes y comportamientos. 
Por otro lado, el patrimonio que siempre estuvo vinculado al pasado desde su nacimiento y definición (del término), abre la puerta y sale a encontrarse con el presente y las necesidades y deseos de su gente, y empieza a vincularse «con otras redes conceptuales: turismo, desarrollo urbano, mercantilización, comunicación masiva ${ }^{4}$, no obstante estos términos (actividades) fueron otrora considerados agresores del patrimonio (García, 1999, p. 16).

Con referencia al tema del presente escrito: el turismo, es uno de los usos sociales que puede dársele al patrimonio cultural, como se ha dicho. El asunto tiene que ver en cómo se usa, el porqué y el cómo y quién lo presenta.

Los profesionales del turismo tienen, entre otras de sus funciones, el encargo de exponer y presentar el patrimonio convertido en atractivo turístico. Son quienes manejarán y compartirán el discurso turístico, es decir, la información que es (o debe ser) fidedigna y confiable, procesada para el entendimiento de públicos diversos. Estos profesionales son también quienes planificarán y gestionarán los espacios patrimoniales-turísticos de tal manera que tengan un uso sostenible y responsable, y permitan su comprensión. Visto así, entonces, no debe soslayarse la labor de estos profesionales, pues se deberá entender su importancia, en concreto, como intermediario entre los valores propios y constitutivos del patrimonio cultural de alguien (algunos y los propietarios) y los intereses de otros (foráneos y turistas).

\section{Patrimonio y turismo}

El turismo es una actividad sociocultural, quizá las más importante de estos tiempos. A propósito, Valdez (2002) señala que:

Es un hecho incontestable que al hablar de turismo estamos hablando de una de las dimensiones más importantes de la cultura del hombre. El individuo se cultiva viajando y al revalorizarse a sí mismo a fuerza de viajar, se motiva aún más por entrar en contacto con otras culturas, paisajes y contextos. (p. 85)

\footnotetext{
4 No son los únicos usos: educativo, político, publicitario, son algunos de otros usos.
} 
Pasar de 25 millones de desplazamientos en 1950 a 1323 millones en 2017 es bastante elocuente acerca del crecimiento y magnitud de esta actividad según la Organización Mundial del Turismo - OMT (2018) y de los espacios sociales que puede invadir y afectar.

La relación turismo-patrimonio debe ser entendida como positiva (o al menos no invariablemente negativa), pues no se debe negar que:

El patrimonio en su más amplia definición siempre ha estado vinculado con la motivación de los viajes y por tanto con el turismo, la diferencia es que hoy día hay una intencionalidad clara de que el patrimonio cultural se constituya en recurso y proporcione beneficios. (Elías, 2009, p. 28)

Y es que el turismo es la actividad que puede generar los recursos económicos que servirían para la gestión del patrimonio, lo que Crespi y Planells (2003) han llamado 'turistización' del patrimonio. Esta generación de recursos económicos tampoco debe ser vista como la panacea, ni puede reducirse al turismo, en su relación con el patrimonio, a su arista económica, pues no debe negarse que en nombre de la generación de ingresos económicos, en algunos casos el turismo ha sido el primer agresor del patrimonio, ya sea a sabiendas o no, voluntaria o involuntariamente: mírese Machu Picchu como ejemplo. Más adelante se retomará el tema de los beneficios del turismo para el patrimonio.

Pero claro, cuando aquí se habla de la práctica del turismo en espacios patrimoniales, en realidad se espera que esta sea respetuosa, responsable y sostenible. A propósito, recientemente, en 2017, el doctor Alberto Martorell, presidente de ICOMOS $^{5}$ Perú, en el marco de la conferencia: Las convenciones UNESCO para la protección y salvaguarda del patrimonio cultural. Un marco global para el diseño de políticas públicas de la Cátedra $\mathrm{UNESCO}^{6}$ de la Universidad de San Martín de Porres $^{7}$ (titulada: Patrimonio

Siglas en inglés de International Council on Monuments and Sites. En español: Consejo Internacional de Monumentos y Sitios. ICOMOS, por sus siglas en inglés.

6 Siglas en inglés de United Nations Educational, Scientific and Cultural Organization (UNESCO). En español: Organización de las Naciones Unidas para la Educación, la Ciencia y la Cultura.

7 UNESCO a través de las Cátedras busca promover el avance y mejora en la investigación y capacitación sobre el tema que le da nombre a cada Cátedra creada. 
Cultural y Turismo Sostenible), decía que al turista «había que enseñarle a ser turista». Esta frase encierra en sí la idea de un turista nuevo, uno cada vez más respetuoso; para ello las gestiones deberán también generar o adecuar las condiciones para un turismo así. Es un tema de oferta (con todos sus actores) y demanda; de responsabilidad de ambas.

Ahondando en los beneficios del turismo para con el patrimonio: además del aspecto económico, está el emocional, 'identitario' (si se permite el uso del término) o cultural y social. En concreto, ver, sentir y escuchar que lo propio es valorado por el otro, repercute en el orgullo y autoestima del 'dueño'; se refleja, esto, en el reforzamiento de la identidad cultural de los poseedores del patrimonio abierto al turismo y a una mejor vida en sociedad.

En contraposición, las ciudades a través de su patrimonio hablan y el turista oye, capta el mensaje de esos bienes y manifestaciones. Lo importante, llegados a este punto, es que el intermediario sepa transmitir ese mensaje; que el profesional del turismo sepa que lo que dice (y cómo lo dice) será relevante en la experiencia del visitante, y que por lo tanto, el discurso turístico deberá sustentarse en investigaciones serias para correlacionarse con la experiencia. El patrimonio dice, pero el guía turístico ${ }^{8}$ de alguna manera será su voz, su intérprete.

La Dra. Alemán (2014), a propósito, analiza la conceptualización e importancia de la interpretación del patrimonio. Tema que se erige en este momento como pertinente e ineludible. Esta metodología de comunicación del patrimonio se define según Guerra, Sureda y Castells (2009, p. 11) como «el arte de revelar in situ el significado del legado natural o cultural al público que visita esos lugares en su tiempo libre» (como se citó en Alemán, 2014, p. 307). A continuación, se desglosará esta definición y se mirará desde el turismo.

Primero, cuando se habla de revelar in situ el significado natural o cultural, será importante considerar para ello a los profesionales del turismo, por lo que su formación deberá ser amplia y a la vez profunda, debido a su alta

Una de las tantas ocupaciones propias del profesional del turismo. 
responsabilidad. Al hablar de público, en realidad, se debe entender que se hace referencia al plural: públicos. Y es que los grupos que se presentan ávidos por acercarse al bien mostrado no siempre son homogéneos, por lo que el profesional, objeto de este estudio, deberá estar preparado para lograr comunicar la esencia de ese bien patrimonial. Finalmente, se hace alusión al tiempo libre, condición sine qua non (junto con el desplazamiento) del turismo. El visitante, dada la motivación de su visita, buscará vivir momentos de esparcimiento y/o aprendizaje, no sin olvidar por supuesto, que se encuentra haciendo uso de su tiempo 'fuera de responsabilidades', o sea, la visita, sin perder la seriedad, deberá ser amena o entretenida, para ello el profesional tendrá que saber cómo organizarla y conducirla.

Mendoza, Umbral y Arévalo (2011) van más allá:

Los Licenciados en Turismo con formación en interpretación, es decir, los intérpretes del patrimonio, deben ser fabricantes de servicios, entusiastas profesionales que conectan el patrimonio con el público, así como diseñadores de exposiciones, educadores ambientales, planificadores, gestores del patrimonio y guías intérpretes utilizando metodologías y técnicas ya desarrolladas pero también innovando. (p. 73)

En este punto no está de más recordar que el patrimonio, como se dijo anteriormente, es primero prerrogativa de la comunidad, solo después y si ellos lo quieren, un lugar o espacio a mirar por ojos extraños, pero interesados. En ese sentido, el turismo debe tener como fines satisfacer al turista y generar beneficios al poblador local o receptor. No obstante, a continuación se analizará el primer propósito: la satisfacción basada en la experiencia del visitante y se terminará diciendo algo sobre el segundo punto.

Sobre la experiencia turística se ha dicho:

Es una construcción individual, personal, y por lo tanto subjetiva. Partiendo de esta premisa se debe entender que la experiencia turística es en realidad la sucesión de una serie de experiencias resultado del «consumo» de servicios, y de la vivencia de momentos 
a lo largo del viaje turístico. Uno de esos «momentos» es la visita a los atractivos turísticos, corazón y razón de ser de los desplazamientos por turismo. (Alberca, 2017, p. 22)

Entonces, el turista va acumulando experiencias a lo largo de su recorrido en el que va interactuando con lugares y personas. Ahora bien, el profesional es gran responsable de que esas experiencias parciales y la global sean satisfactorias; le agrega, a este reto, la dificultad de comprender y servir a personas de diferentes culturas y con diferentes expectativas.

Por último, las universidades (como centros de formación) no han sabido traducir en sus currículos el interés por los beneficios de los pobladores locales como un fin del turismo, según los resultados obtenidos en esta investigación, donde solo el $3 \%$ de los cursos en los planes de estudio ${ }^{9}$ se ocupan de temas vinculados a la sostenibilidad (en cuanto a los aspectos socioculturales y ambientales/naturales).

\section{Turismo cultural}

El turismo es sobre todo una actividad social y cultural. Ocurre el encuentro entre los receptores y turistas. En el caso de los primeros, se trata, «no solo de seres humanos comúnmente denominados residentes, sino de un espacio geográfico con especifidades sociales, económicas, culturales, ecológicas y políticas que se conjugan para construir la complejidad comunitaria» (Monterrubio, 2009, como se citó en Alberca, 2014, p. 74); en otras palabras, dentro del concepto de comunidad receptora, se incluyen las dinámicas sociales internas que redundan en su forma de vivir o de entender el mundo, expresado en su patrimonio. Por eso, el turismo como actividad organizada y gestionada a nivel micro y macro no puede tomar solo al patrimonio como un recurso sin propiedad específica, sino que, por el contrario, deberá tener en cuenta, y para todo el proceso, a los locales o receptores que son lo que finalmente se abren al foráneo.

Se ha estudiado los planes de estudios registrados en SUNEDU y disponibles en la web. Se ha cuantificado los cursos vinculados a patrimonio, turismo cultural, sostenibilidad y naturaleza. 
El turismo cultural, según la Secretaría de Turismo de México (SECTUR) puede ser entendido como:

El conjunto de todas aquellas actividades que se realizan en contacto directo con el patrimonio tangible e intangible de una nación, basada en la sustentabilidad, que se consolida como un elemento importante que coadyuva al desarrollo y progreso, tanto de los actores como de las comunidades involucradas en este sector. (como se citó en Ávila, 2011, p. 19)

Es decir, el turismo cultural está generalmente relacionado con el patrimonio ya que «se centra en la visita de lugares que destacan por su riqueza patrimonial, principalmente monumental y artística, y por la idiosincrasia de su gente» (Crespi \& Planells, 2003, p. 15). El turista va buscando lo auténtico (en lo posible) y el patrimonio le ofrece, quizá, lo más propio de los locales, lo que es reflejado en bienes y manifestaciones oriundas, particulares.

Ávila (2011) propone tres condiciones para hablar de turismo cultural:

1. El deseo de conocer y comprender las obras y a las personas con quienes contactará.

2. Uno o más productos de significación cultural (monumentos, obras de arte, espectáculos, intercambio de ideas, etc.).

3. La existencia de un mediador (persona o plataforma escrita o audiovisual que destaque el valor y favorezca la presentación, explicación, etc. de lo mostrado).

Es importante también señalar que Piñanes (como se citó en Morére \& Perelló, 2013) sostiene que para la práctica del turismo cultural hay otras tres condiciones que cumplir, y que interactúan constantemente, como son el deseo de cultivarse por parte del turista, es decir, «conocer y comprender objetos, las obras, los hombres»; el usar uno o más recursos de corte y significación cultural, ya convertidos en recursos turísticos; y además la intervención de un intermediario, persona, documento, material audiovisual $\mathrm{u}$ otros que sean capaces de presentarlos. 
Puede notarse, en consecuencia, que los planteamientos de Ávila (2011) y Piñanes (como se citó en Morére \& Perelló, 2013) coinciden en que para que haya turismo (el cultural en particular), es necesario un encuentro entre demanda y oferta, y la existencia además de un intermediario. Esto resulta relevante pues permite poner bajo el foco los aspectos referentes a los actores principales de turismo: locales y turistas. Si bien la primera condición se enfoca claramente en el visitante, la segunda, creemos, debe mirarse como dirigida a las comunidades receptoras o locales, en tanto son sus recursos patrimoniales los que se utilizarán turísticamente. Martorell (2017), al respecto sostiene:

En lo relativo al fenómeno del turismo, es necesario recentrar los procesos de planificación en torno a los valores estables, permanentes, continuos y de alta significatividad e impacto, que son los generados por la población local y su patrimonio. Deben hacerse esfuerzos por desarrollar en el turista capacidades de disfrute de la experiencia cultural en su mayor autenticidad, convirtiendo al turismo en un fenómeno de encuentro de valores, respeto y aprendizaje mutuos. (p. 53)

En cuanto a la tercera condición para el turismo cultural: la intermediación propuesto por Ávila (2011) y Piñanes (como se citó en Morére \& Perelló, 2013). Aquí reaparece la figura del profesional del turismo, no solo como guía, facilitador o brindador de servicios, sino también como planificador. El turismo no consiste solo en la combinación (turista/visita/marcador), como estructura de la atracción, a decir de MacCannell (2003); el turismo es encuentro o encuentros, y dentro de esa maraña de acercamientos puede aparecer el profesional del turismo, vestido de sus diferentes facetas o responsabilidades, para interactuar y propiciar experiencias satisfactorias.

Por último, vale señalar que «el turismo cultural tiene las posibilidades de convertirse en el gran factor de sostenibilidad, de encuentro y desarrollo» (Martorell, 2017, p. 99), lo importante es enfocar las acciones respetando siempre la esencia del patrimonio observado o disfrutado, y generar beneficios a los locales y experiencias únicas e inolvidables a los turistas. 


\section{Estudios de turismo en el Perú}

Jafar Jafari (2005) en su famoso artículo El turismo como disciplina científica, ha clasificado cronológicamente en cuatro plataformas las reflexiones sobre el turismo: apologética, precautoria, adaptativa y científico-céntrico, resaltando en la primera los aspectos positivos del turismo; en la segunda, los impactos negativos; en la tercera, las alternativas que equilibran esos impactos; y en la cuarta, la búsqueda de teorización del turismo.

Es en este marco que los estudios de turismo han aumentado. Como el mismo Jafari señala: se empezó incluyendo al tema dentro de otras materias más consolidadas, y se ha llegado a ofrecer ahora, incluso, programas de doctorado en turismo. No obstante, «a pesar de sus logros, académicos, publicaciones y producciones, la academia de turismo continúa siendo una institución cuya influencia en la sociedad se encuentra de forma limitada, si se quiere con escasa o nula gravitación al quehacer cotidiano» (Korstanje, 2016, párr. 1), esto porque es una disciplina joven académicamente hablando. Es compleja, dinámica y está en desarrollo, lo que no ha permitido aún generar un cuerpo de conocimientos estructurado. Muñoz (2017) escudriña este asunto en su artículo titulado iEs el conocimiento del turismo una ciencia? Y si no lo es, ipuede serlo?, donde pone de manifiesto las confusiones que existen alrededor de la investigación y teorización del turismo, concluyendo que el turismo no es una ciencia, al menos, no por ahora.

Otra particularidad de los estudios profesionales en turismo es que en el 83.3\% (dato obtenido en la presente investigación) la denominación del grado académico es acompañada de alguna actividad que es, además constitutiva, como por ejemplo, turismo y hotelería, turismo y patrimonio, administración en turismo, gestión turística, y otros. Esto se cree, denota la desconfianza, al menos comercial, en el turismo por sí solo como nominación para una carrera profesional. Aunque por otro lado, no hace más que reflejar la complejidad de esta actividad social.

Pero nos interesan, en este trabajo, los estudios de pregrado, los que forman y sientan las bases conceptuales disciplinares. 
El turismo, es una disciplina que se estudia en el Perú a nivel universitario y técnico. Según la Superintendencia Nacional de Educación Superior Universitaria - SUNEDU (30 de julio de 2018) 86 universidades ofrecen esta carrera; teniendo mayor concentración de la oferta académica en Lima $(41.7 \%)$.

Los estudios del turismo son relativamente jóvenes, son complejos y están dispersos, y además, están aún en formación. Por tal motivo, el turismo se apoya en diversas disciplinas y ciencias para intentar descifrar su 'ser'. Muestra de ello, es la Figura 1 donde puede verse claramente la transversalidad del turismo y las relaciones con las diferentes disciplinas o ciencias.

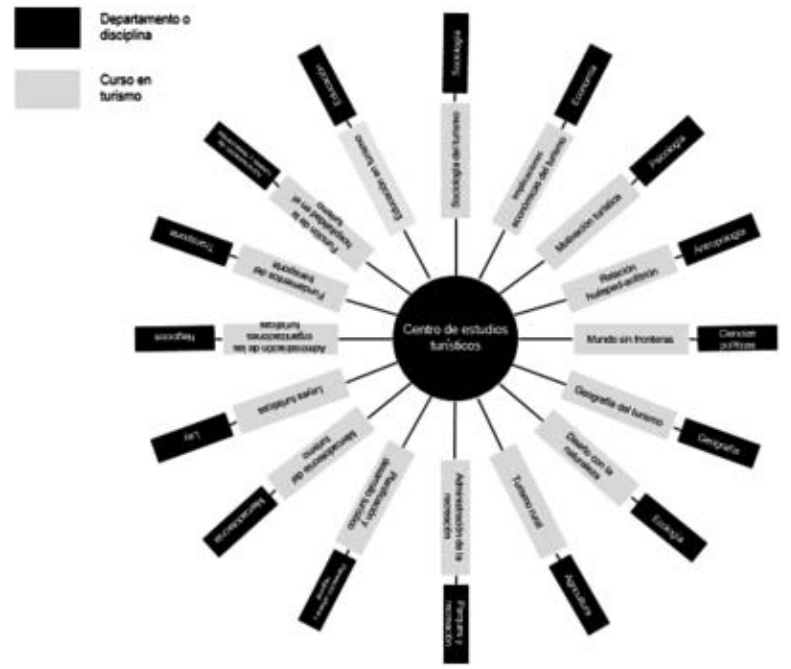

Figura 1. Fundamento interdisciplinar de los estudios turísticos.

Pero, para analizar la formación del profesional del turismo (y su orientación hacia el patrimonio en ese proceso) se plantea la revisión de la presencia de cursos vinculados a las principales aristas del patrimonio que, a decir, ya se ha venido esbozando en las líneas precedentes. El patrimonio o la formación para él, se lee en los cursos cuyos temas giran alrededor del patrimonio (cultural y natural), la naturaleza, el ambiente, la sostenibilidad, el turismo rural comunitario (TRC), el ecoturismo, el turismo cultural y otros. 
Ahora bien, se ha considerado conveniente revisar lo referente a la formación del profesional del turismo porque son ellos el resultado de los conocimientos aprehendidos, la experiencia de sus docentes, sus prácticas y los valores recibidos. Y, si miramos el primer componente, es decir, los conocimientos, el profesional del turismo los adquiere de una amplia gama disciplinas y ciencias con los que se relaciona (ver Figura 1), lo que le permite tener una visión amplia del mundo globalizado, la sociedad y de la actividad turística. Es esa formación (vista en las mallas curriculares y planes de estudio), en todo caso, coherente con su complejidad, expresada en su falta de definición y falta de objeto concreto de estudio: ien turismo, se estudia principalmente la satisfacción del turista, del local, la generación de servicios, la gestión territorial, sus impactos, etc.?

\section{Método}

El diseño es no experimental descriptivo y responde a un enfoque cuantitativo, de alcance descriptivo.

Se ha considerado como objeto de análisis los planes y mallas curriculares de las universidades registradas (86) en SUNEDU (según disponibilidad); una vez identificadas se procedió a la revisión de cada malla o plan curricular, vía internet.

Se utilizó como instrumento una matriz donde se fue vertiendo la información recabada tras la revisión, para su posterior análisis.

De las 86 universidades que registraron sus carreras de turismo (con todas sus denominaciones) a nivel nacional en SUNEDU, al 30 de julio de 2018, 72 $(84 \%)$ lo hicieron a nivel de pregrado y 14 (16\%) a nivel de postgrado. De estas, son de interés para este estudio los planes y mallas curriculares de pregrado: 72, aunque de estos, solo presentan información o existen efectivamente 49 (pueden estar registrados, pero no operar, por ejemplo), siendo este número final o válido de la población de estudio. La recolección de datos se hizo durante los meses de julio y agosto del año 2018. 


\section{Resultados}

Lima es la región que mayor oferta de estudio profesional en turismo presenta (a nivel de pregrado), con $41.7 \%$, le siguen Cusco, Arequipa y Lambayeque con $6.9 \%, 5.6 \%$ y $5.6 \%$ respectivamente.

Tabla 1

Oferta de carreras profesionales según región

\begin{tabular}{cccc}
\hline $\mathrm{N}^{\circ}$ & Región & Conteo & Porcentaje \\
\hline 1 & Lima & 27 & $37.5 \%$ \\
& Lima - Huacho & 3 & $4.2 \%$ \\
& Lima total & 30 & $41.7 \%$ \\
2 & Cusco & 5 & $6.9 \%$ \\
3 & Arequipa & 4 & $5.6 \%$ \\
4 & Lambayeque & 4 & $5.6 \%$ \\
5 & Iquitos & 3 & $4.2 \%$ \\
6 & Otros & 26 & $36.10 \%$ \\
\hline
\end{tabular}

Nota: Elaboración propia.

Asimismo, siempre según información de SUNEDU, la oferta de postgrado llega a los 12 programas (8 en Lima y 4 en otras regiones), de estos 11 son de maestría y 1 de doctorado (en Lima).

Se ha clasificado las denominaciones de los grados académicos (bachiller) ofrecidos, para ver así la orientación de las carreras de turismo. Se tienen los siguientes resultados:

Tabla 2

Clasificación de carreras ofrecidas según denominación del grado de bachiller

\begin{tabular}{cccc}
\hline $\mathrm{N}^{\circ}$ & Denominación & Conteo & Porcentaje \\
\hline 1 & Turismo y hotelería & 13 & $18.10 \%$ \\
2 & Turismo, hotelería y gastronomía & 12 & $16.70 \%$ \\
3 & Turismo & 12 & $16.70 \%$ \\
4 & Turismo y educación & 8 & $11.10 \%$ \\
5 & Administración en turismo & 17 & $23.60 \%$ \\
\hline
\end{tabular}

Nota: Elaboración propia. 
Como puede verse, predomina la orientación hacia la administración y la hotelería. Asimismo, se resalta la casi inexistencia del término patrimonio en las denominaciones de los grados académicos. Si bien la presencia del término no es un indicativo definitivo en el proceso de formación, sí es una referencia a considerar.

Por otro lado, se ha clasificado en cuatro grupos los cursos vinculados al patrimonio (sobre la base de los planes revisados) denominándolos: Patrimonio, Turismo cultural, Naturaleza y Sostenibilidad; estos grupos responden así al intento de cubrir temáticamente lo relacionado al patrimonio.

Tras la revisión de los planes y mallas curriculares que las universidades ofrecen a sus potenciales y reales estudiantes de la carrera de turismo, se tiene que: En cuanto a la primera clasificación o grupo Patrimonio, se ha considerado los cursos vinculados a temas como patrimonio cultural, arqueología, museos, folklore y derivados o variantes. En cuanto a Turismo cultural, se cuentan los cursos que tienen la misma denominación y los derivados o variantes. Respecto al grupo Naturaleza, se incluyen los cursos patrimonio natural, áreas naturales protegidas (ANP), ambiente, ecología y derivados o variantes. Finalmente, Sostenibilidad, tiene los cursos sobre ecoturismo, sostenibilidad, desarrollo sostenible, turismo rural comunitario y derivados o variantes.

Tabla 3

Clasificación de los cursos según temática

\begin{tabular}{|c|c|}
\hline Grupo/clasificación & Temática de los cursos \\
\hline Patrimonio & $\begin{array}{l}\text { Patrimonio cultural, arqueología, museos, folklore } \\
\text { y derivados o variantes. }\end{array}$ \\
\hline Naturaleza & $\begin{array}{l}\text { Patrimonio natural, áreas naturales protegidas } \\
\text { (ANP), ambiente, ecología y derivados o } \\
\text { variantes. }\end{array}$ \\
\hline Turismo cultural & Turismo cultural y derivados o variantes. \\
\hline Sostenibilidad & $\begin{array}{l}\text { Ecoturismo, sostenibilidad, desarrollo sostenible, } \\
\text { turismo rural comunitario y derivados y variantes. }\end{array}$ \\
\hline
\end{tabular}

Nota: Elaboración propia. 
De manera general, la carrera presenta un promedio de 66.8 cursos divididos en 10 semestres académicos. Los cursos vinculados a Patrimonio son 1.6 cursos en promedio, los que representan el $2.40 \%$; Naturaleza, 1 curso en promedio (1.50\%); Turismo cultural, 0.1 curso en promedio (0.15\%); y Sostenibilidad, 1 curso en promedio $(1.50 \%)$.

Puede leerse, entonces, que el promedio de todos estos cursos, frente al total, es de $5.55 \%$, y que además el $3.9 \%$ de los cursos en promedio se relacionan al patrimonio cultural y natural más claramente. Además, puede colegirse que apenas se refleja el interés por la sostenibilidad (en lo sociocultural) y el turismo cultural (ambos grupos de cursos alcanzan el 1.65\%), que es, de cara a esta investigación, la mejor forma de presentar el patrimonio cultural al visitante.

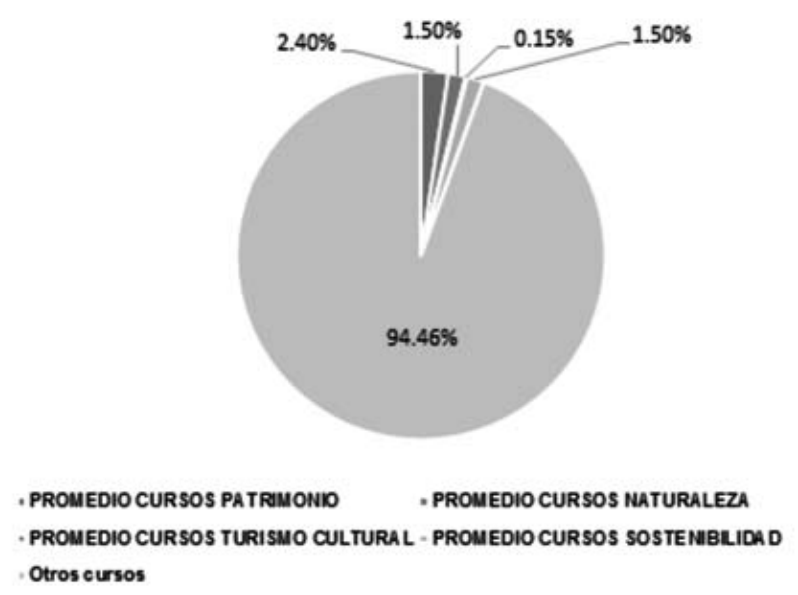

Figura 2. Porcentajes de cursos vinculados al patrimonio, naturaleza, turismo cultural y sostenibilidad según los planes y mallas curriculares.

Con respecto a los créditos, la carrera en promedio exige el cumplimiento de 209.9 créditos. Patrimonio tiene 3.2 créditos como media; Naturaleza 3.1; Turismo cultural 3.5; y Sostenibilidad 3; en total suman 12.8 créditos en promedio, lo equivalente al $6.1 \%$ del creditaje de la carrera. Puede notarse entonces, que el número de créditos promedio se encuentra dentro del promedio, pues los cursos de cualquier índole no suelen exceder los cuatro créditos. 


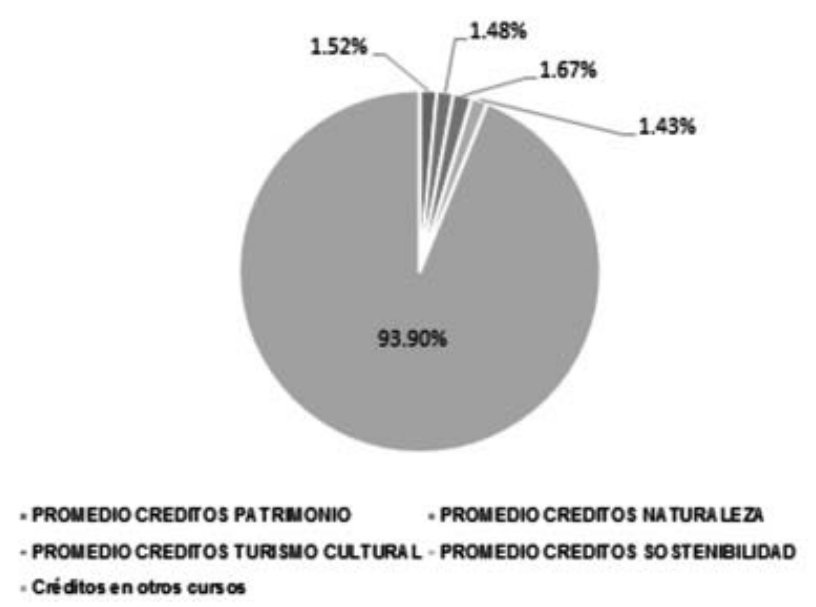

Figura 3. Porcentajes de créditos vinculados al patrimonio cultural, natural, turismo cultural y sostenibilidad según los planes y mallas curriculares.

A continuación los resultados correspondientes al grupo Patrimonio:

El $46 \%$ de los planes y mallas curriculares incluyen solo 1 curso de este grupo, mientras que solo 2 universidades presentan 4 cursos de este grupo; 4 universidades no presentan ningún curso vinculado. Las demás casas de estudio se dividen entre la presencia de 2 y 3 cursos en sus planes y mallas a lo largo de la carrera. Leyéndolo de otra manera, se tiene que el $92 \%$ de los planes incluye al menos 1 curso. Esto es relevante dada la profunda relación entre el turismo y el patrimonio en el caso del Perú, a pesar de ser pocos los cursos (1.6 cursos en promedio) sobre el tema.

Asimismo, es el tercer ciclo en el que más veces aparecen los cursos de este grupo. Los ciclos más y menos avanzados en que se imparten estas materias son el décimo y primer ciclo respectivamente.

Según lo visto, entonces, se tiene que estos cursos se encuentran mayormente en el primer tercio de la carrera, lo que implica que son llevados generalmente por los alumnos más jóvenes. En adelante no se reforzarían estos temas. De los planes que exponen la cantidad de créditos por curso, se obtuvo que el promedio de créditos de este grupo de cursos fue de $3.2(1.52 \%)$. 
Es importante señalar que la oferta turística del Perú se basa en el patrimonio, especialmente en el cultural, por lo que la formación en este, como en otros temas vinculados exige mayor amplitud y profundización expresada en más cursos generales y especializados.

Los resultados en el grupo Naturaleza:

En 22 ocasiones se tiene solo un curso de este tipo o clasificación. Solo una universidad presenta 4 cursos y 15 no los presentan en ningún caso, lo que equivale al 30\% de las universidades estudiadas. En general más del 69\% sí presentan algunos de estos cursos como parte de su oferta académica, lo que es alentador, aunque insuficiente.

Sin embargo, el porcentaje de los que no ofrecen estos cursos (30\%) no debe dejarse de lado, si se considera que el turismo en el Perú pretende acercarse más a espacios naturales como a las ANP, como forma de diversificar la oferta turística.

Según los datos, es el quinto ciclo en que más veces se dictan estos cursos, con un promedio de 3.1 créditos (1.48\% respecto de los 209.9 créditos en promedio de la carrera).

Los resultados en el grupo Turismo cultural:

Se observa que están presentes solo en 5 planes o mallas y solo con un curso que además, se dicta sobre todo en octavo ciclo.

Se tiene que los ciclos (mayor y menor) en que se dicta esta materia son el noveno y cuarto ciclo.

En lo referente a los créditos de los planes o mallas que se estudiaron, se tiene que de los 209.9 créditos de la carrera en promedio, estos estudios alcanzan los 3.5 en promedio, o sea, el 1.67\%.

Los resultados en el grupo Sostenibilidad:

En 22 ocasiones aparecen una sola vez y solo una vez con 4 cursos a lo largo de la carrera. En el 69\% de las veces se hizo presente al menos un curso de 
este grupo. Asimismo, 15 universidades no presentan estos temas en ningún caso, lo que equivale a casi el $31 \%$. Estas cifras son importantes pues ponen de manifiesto la limitada presencia de cursos sobre sostenibilidad. El turismo cultural, basado en el patrimonio, debe ser sostenible y respetuoso, siendo necesario reflexionar y actuar sobre el tema en las universidades.

En promedio estos cursos tienen 3 créditos (1.43\% de los créditos totales de la carrera) y se dictan preferentemente en el séptimo ciclo. Y los ciclos máximos y mínimos en que se imparten estas materias son: décimo y primero, respectivamente.

\section{Conclusiones}

Tras el análisis de los planes y mallas curriculares de las carreras de turismo ofrecidas en el Perú y registradas en SUNEDU, se tiene que la presencia de cursos vinculados al patrimonio, es decir, cursos referidos a patrimonio cultural, naturaleza/ambiente, turismo cultural y sostenibilidad, son insuficientes (3.7 cursos en la carrera equivalentes al 5.5\%), más aún, si se considera la relación cercana y bidireccional -en el caso del Perú- entre patrimonio y turismo. Consideramos que debería ser un promedio de cinco los cursos sobre patrimonio que se ofrezcan, sin embargo, lo recomendable sería un número mayor, de tal forma que pueda abordarse más ampliamente este tema.

Atendiendo la relación patrimonio-turismo para la formación de los profesionales del turismo, la existencia de Cátedras UNESCO es relevante. En el Perú, la Universidad de San Martín de Porres (USMP) es la única institución poseedora de una Cátedra UNESCO (titulada acertadamente Patrimonio Cultural y Turismo Sostenible) relacionada al patrimonio cultural. Esta Cátedra constituye, en el ámbito peruano, una herramienta valiosa que permite a los profesionales del turismo, fundamentalmente de esta casa de estudio, tener una visión amplia, profunda y reflexiva del tema patrimonio, mejorando así su formación y acercándose a lo sugerido en esta investigación.

El turismo es una actividad compleja y dinámica, así como una disciplina emergente, pero sin objeto de estudio claramente definido. Esto se refleja en la diversidad de denominaciones de los grados académicos de bachiller que 
se ofrece en las distintas universidades peruanas. Esta diversidad, también, es una manera de cubrir temáticamente, desde el mundo académico, a la actividad turística.

Por último, la oferta de postgrado debería ampliarse y descentralizarse. El número de maestrías y doctorados es reducido, siendo 12 , lo que no sintoniza con la necesidad de formación constante de los profesionales en general, en particular los de turismo, dadas sus múltiples tareas y responsabilidades.

\section{Referencias}

Alberca, F. (2014). Potencial turístico de Ayabaca como destino cultural. Una nueva metodología (Tesis de maestría). Universidad de San Martín de Porres, Lima, Perú.

Alberca, F. (2017). El turismo de carreteras. Oportunidades y desafíos. Cultura, 31, 13-35. Recuperado de http:/l www.revistacultura.com.pe/revistas/RCU_31_turismo-de-carretera-en-el-Peru-oportunidades-y-desafios.pdf

Alemán, A. (2014). Reflexiones sobre interpretación del patrimonio. Cultura, 28, 305-315. Recuperado de http:/l www.revistacultura.com.pe/revistas/RCU_28_1_reflexiones-sobre-la-interpretacion-del-patrimonio.pdf

Ávila, R. (2011). Turismo cultural en México. Alcances y perspectivas. México D. F.: Trillas.

Carvalho, A. V., \& Funari, P. A. (2012). Memoria y patrimonio: diversidades e identidades. Antípoda, 14, 99-111. Recuperado de http://www.scielo.org.co/pdf/antpo/n14/n14a05.pdf

Crespi, M., \& Planells, M. (2003). Patrimonio cultural. Madrid: Síntesis.

Elías, L. (2009). Otras formas de turismo. México D. F.: Trillas.

García, N. (1999). Los usos sociales del patrimonio. En E. Aguilar (Ed.), Patrimonio Etnológico. Nuevas perspectivas de estudio (pp. 16-33). Consejería de Cultura. Junta de Andalucía.

Jafari, J. (2005). El turismo como disciplina científica. Política y Sociedad, 42(1), 39-56. Recuperado de https:// revistas.ucm.es/index.php/POSO/article/viewFile/POSO0505130039A/22996

Korstanje, M. (2016). Infructuoso prestigio: actuales obsesiones y temores de los turismólogos. Turydes, 21. Recuperado de http://www.eumed.net/rev/turydes/21/turismologos.html

MacCannell, D. (2003). El turista: una nueva teoría de la clase ociosa. Barcelona: Melunisa.

Martorell, A. (2017). Turismo cultural: reflexiones para un encuentro sostenible entre turismo y cultura. Lima: Fondo editorial de la Universidad de San Martín de Porres.

Mendoza, M., Umbral, M., \& Arévalo, M. (2011). La interpretación del patrimonio, una herramienta para el profesional de turismo. El Periplo sustentable, 20, 9-30. Toluca: Universidad Autónoma del Estado de México. Recuperado de http://www.redalyc.org/pdf/1934/193417856002.pdf

Morére, N., \& Perelló, S. (2013). Turismo cultural: patrimonio, museos y empleabilidad. Madrid: Fundación EOI. Recuperado de https://books.google.com.pe/books?id=fDdYDWAAQBAJ\&printsec=frontcover\&dq $=$ Mor\%C3\%A8re+Molinero\&hl=es $-419 \& s a=X \& v e d=0$ ahUKEwjgqKbqrszcAhUovlkKHTRyAa4 Q6AEIJZAA\#v=onepage\&q=Mor\%C3\%A8re\%20Molinero\&f=false 
Muñoz, F. (2017). ¿Es el conocimiento del turismo una ciencia? Y si no lo es, ¿puede serlo? Turismo y Sociedad, XX, 27-48. Recuperado de https://doi.org/10.18601/01207555.n20.02

Organización Mundial del Turismo - OMT. (2018). Reporte Anual 2017. Madrid: Organización Mundial del Turismo. Recuperado de https://doi.org/10.18111/9789284419807

Pastor, M. J. (2003). El patrimonio cultural como opción turística. Horizontes Antropológicos, 9(20), 97-115. Recuperado de https://dx.doi.org/10.1590/S0104-71832003000200006

Sariego, I. (2014). Espacios turísticos rurales para el desarrollo sostenible: el turismo rural comunitario en el Perú. Turismo y Patrimonio, 8, 47-61. Recuperado de http://ojs.revistaturismoypatrimonio.com/index.php/typ/ article/view/38/30

Superintendencia Nacional de Educación Superior Universitaria - SUNEDU. (30 de julio 2018). Lista de carreras autorizadas. Recuperado de https://www.sunedu.gob.pe/lista-carreras-autorizadas/

Valdez, R. (2002). Turismo cultural: la experiencia mexicana. En J. García y M. Poyato (Coord.), La función social del patrimonio histórico: el turismo cultural (pp. 83-104). Cuenca: Ediciones de la Universidad de Castilla La Mancha. Recuperado de http://books.google.com.pe/books?id=8_nfnBp4Rg4C\&printsec= frontcover\&dq=turismo+cultural\&source=bl\&ots=0ZhvIZm3wW\&sig=dKgo1_2awuE70BJRdwkIVZDpY4\&hl= es\&sa=X\&ei=ndxjUM3bK_CM0QHDIYGIDA\&ved=0CDgQ6AEwAw\#v=onepage \&q=turismo\%20 cultural\&f=false

Urry, J. (2004). La mirada del turista. Lima: Universidad de San Martín de Porres. 